\title{
Impact on the Quality of Life of Older Adults Who Use Inadequate Dental Prostheses: A Cross-Sectional Study
}

\author{
Michelle Almeida Silva ${ }^{1}$, André Ulisses Dantas Batista2 ${ }^{\circledR}$, Mauro Henrique Nogueira Guimarães \\ Abreu $^{3}$ (D), Franklin Delano Soares Forte ${ }^{1}$ (i)
}

\begin{abstract}
${ }^{1}$ Department of Clinic and Public Health Dentistry, Health Sciences Center, Federal University of Paraíba, João Pessoa, PB, Brazil.

2Department of Restorative Dentistry, Health Sciences Center, Federal University of Paraíba, João Pessoa, PB, Brazil. ${ }^{3}$ Department of Community and Preventive Dentistry, School of Dentistry, Federal University of Minas Gerais, Belo Horizonte, MG, Brazil.
\end{abstract}

Author to whom correspondence should be addressed: Franklin Delano Soares Forte, Department of Clinic and Public Health Dentistry, Health Sciences Center, Federal University of Paraíba, University City, João Pessoa, PB, Brazil. 58051 900. Phone: +55 8332167251 . E-mail: franklinufpb@gmail.com.

Academic Editors: Alessandro Leite Cavalcanti and Wilton Wilney Nascimento Padilha

Received: 25 May 2019 / Accepted: 18 March 2020 / Published: 24 April 2020

\footnotetext{
How to cite this article: Silva MA, Batista AUD, Abreu MHNG, Forte FDS. Impact on the quality of life of older adults who use inadequate dental prostheses: a cross-sectional study. Pesqui Bras Odontopediatria Clín Integr. 2020; $20: e 4713$. https://doi.org/10.1590/pboci.2020.074
}

\begin{abstract}
Objective: To investigate the impact of inadequate prostheses on older adult's quality of life at the Integrated Health Center for Older Adults in the northeastern city of Brazil. Material and Methods: A cross-sectional study involving 147 older adults aged 60-90 years old in João Pessoa, Brazil. Interviews and oral examinations were carried out to collect demographic characteristics (age and gender) and clinical dental measures (use of inadequate upper and/or lower dental prosthesis) and Oral Health Impact Profile (OHIP-14 Questionnaire). The Pearson Chi-square and Fisher's exact tests were used to evaluate the association between the OHIP-14 dimensions and the use of unsatisfactory prostheses $(\mathrm{p}<0.05)$. Results: The sample consisted of $90.5 \%$ of women being a mean age of $69.86( \pm 6.60)$ years. Individuals with inadequate prostheses had a higher impact on quality of life, with a predominant prevalence ratio for developing physical pain $(\mathrm{PRR}=3.52$; $\mathrm{CI}=4.69-2.65)$, psychological discomfort $(\mathrm{PRR}=5.0$; $\mathrm{CI}=5.85$ $4.26)$ and psychological inability $(\mathrm{PRR}=1.71$; $\mathrm{CI}=2.56-1.14)$. Conclusion: The use of inadequate prostheses had a negative impact on the quality of life of the older adult population. Therefore, services, which provide health care for older adults, should overcome this reality by providing broad access to oral rehabilitation that is appropriate to the needs of each individual.
\end{abstract}

Keywords: Quality of Life; Oral Health; Aged; Dental Prosthesis. 


\section{Introduction}

Quality of life is defined in many dimensions, and the judgment is subjective and singular. The concept covers a diversity of physical, psychological and social dimensions that can influence each person's well-being and health [1]. Oral problems can directly influence the quality of life of individuals, affecting different dimensions of life and relationship with the world, such as: talking, expressing feelings, self-esteem, chewing, smiling, tasting food or selecting them to eat, feeling attractive and the sentimental relationships [2]. Several changes are consequences of aging, directly impacting the quality of life of the elderly person [3]. So, oral health is one of the factors that are connected to and have a direct influence on the quality of life. When teeth are lacking, there is a need to rehabilitate the mouth with dental prostheses to provide beneficial improvements to these individuals' physical, psychological and social dimensions [4-6].

Dental prostheses are widely used to substitute lost teeth and re-establish the functions of the stomatognathic system, which are essential for daily activities, such as the ability to chew, speak, swallow adequately, smile and other social functions [7,8].

There are studies in the literature pointing out the importance of precise denture base adaptation, setup of the artificial teeth in the right position, establishment of correct centric relation and vertical dimension for maintaining stability and retention of the dental prosthesis [9].

Older adults using dental prostheses have a critical self-perception of their oral health condition and are willing to be understanding when a prosthesis is not of acceptable quality. But in spite of this, they still use it. This situation is also associated with tooth loss throughout life and many use inappropriate prostheses [1012]. Some studies have reported that there is an adaptation to dental prostheses, regardless of their quality $[13,14]$. Studies in which improvement in the quality of life of older adults being associated with technically satisfactory dental prostheses have also been observed [15-17].

For this reason, it is necessary to expand public health policies that aim to increase these individuals' access to public oral rehabilitation services in a way that is universal, effective, and quality. However, in the attempt to provide people with a healthy aging process and better quality of life at advanced ages, Brazil has been seeking to transform its public oral health policies with measures that improve access to oral rehabilitation care since 2004. The Brasil Sorridente (Smiling Brazil) organization began implementing dental prostheses laboratories throughout the entire country, and also Specialized Dental Centers (Centros de Especialidades Odontológicas - CEOs), which aim to offer services of medium complexity dental care for the edentulous population [18,19].

In Brazil, a total of 325 CEOs have Regional Prosthodontic Laboratories (Laboratórios Regionais de Prótese Dentária - LRPD), located in 299 municipalities. In the Northeast, there are 357 CEOS and 141 LRPD [20]. Despite this, the elderly, currently, are from a generation that was not benefited with public oral health policies, such as water fluoridation, access to toothbrush and fluoride toothpaste, access to health education and public policies that effectively contribute to the reduction of dental caries in Brazil during last decades [21]. Therefore, it is possible to note the increase in access to dental services in the last years, however, to meet the entire historical demand for health care that the population needs is still a challenge for Brazil [22]. Thus, it is important that the Oral Health Care Network is organized to allow better access to secondary care; on the other hand, when there is no flow organization, demand can be absorbed by the private sector [22]. Thus, the dental prostheses need to be adequately constructed to have a positive influence on the quality of life. As an example, when dentists are planning dental prostheses, they need to provide appropriate conditions of use such as being in harmony with the temporomandibular joint (TMJ) function, muscle tone, distribution of occlusal 
forces, and correct functional adaptation to the shape and size of the alveolar ridge, as well as taking into account aesthetic aspects [23].

Therefore, this study aims to investigate and report on the impact of inadequate prostheses on older adults' quality of life, given the importance of the association between quality of life in oral health and the conditions of using dental prostheses by older adults.

\section{Material and Methods}

\section{Study Design}

This is an analytical cross-sectional study. The recommendations of the STROBE [24] statement (Strengthening the Reporting of Observational Studies) were applied in this study.

\section{Study Scenario}

This study took place in the city of João Pessoa, in the state of Paraíba, in Northern Brazil. The city has a population of 800,738 and Human Development Index (HDI) of 0.763. Primary healthcare is oriented by the Family Health Strategy with 83.05\% coverage through 193 family health teams, 92.61\% coverage by Community Health Agents ('ACSs'), and 178 Oral Health Teams ('EqSB's) with 78\% coverage. This was a cross-sectional study in a secondary healthcare center of a capital in Northeast Brazil: The Comprehensive Health Center for Older Adults (or CAISI - Centro de Atenção Integral à Saúde do Idoso), which is a referral center for healthcare for older people and is linked to the Municipal Health Department of the city of João Pessoa, Paraíba, Brazil.

The center is exclusively for people aged 60 or over and was created in 2007 and does not have an LRPD linked to oral health services. It offers activities oriented to the needs of older adults, attending people aged 50 years or older daily, and includes a variety of services, among which we highlight: a school of posture, physical activity, courses in 'living with other people', memory stimulation, 'well-being - autonomy independence' - and specialized care (angiology, pharmaceutical care, cardiology, endocrinology, nursing, physiotherapy, geriatric care, gynecology, nephrology, nutrition, odontology, psychology, rheumatology, social service, and speech and hearing care).

\section{Sample Calculation and Selection}

The data was collected from March to July 2015. This figure was determined for a finite population of 500 older adults in the year of the examination. The sampling calculation assumed $69 \%$ usage prevalence of dental prostheses, $5 \%$ error and a 95\% confidence interval [25]. The study's participants were 147 older adults using a dental prosthesis in at least one of the upper or lower jaw. They were all CAISI users aged between 60 and 90, both genders, and randomly selected. Thus, the selected elderly were waiting for their consultations when they were invited to participate in the study. The eligibility criteria considered individuals aged 60 and 90 years old who had signed the informed consent form, completely filled out an interview with no missed items, did not present any physical or/and mental impediment to answering the interview questions, and were using a dental prosthesis in at least one of their jaws.

The participants in the study were submitted to a questionnaire covering aspects of quality of life, and a clinical examination, which evaluated the use and type of dental prosthesis they used, and also whether or not these prostheses adequately performed their functional and aesthetic criteria. 


\section{Pilot Study}

A pilot study was initially conducted to train the examiner in another population with the same age as the sample. The training exercise comprised two stages - theoretical and clinical. The first stage established a theoretical dialog on the OHIP-14; the use of a dental prosthesis [26,27]; and the criteria for checking the conditions of using dental prostheses. These procedures involved analyzing photographs, models of dental prostheses and the WHO guidelines [26].

The second phase was to evaluate the consistency of the clinical analysis. An experienced (goldstandard) dentist trained a single examiner using a sample of 22 older adults, selected at random. The reliability of the examiner was checked twice in two weeks and evaluated by Cohen's Kappa coefficient. The reproducibility of the diagnosis was determined by the intra-examiner reliability $(K=0.90)$. The pilot study results also revealed no misunderstandings regarding the questionnaire methodology and its comprehension; therefore, no changes were deemed necessary.

\section{Non-Clinical Data Collection}

Data were collected by an interview in the consulting rooms of the health service unit itself. A trained researcher read the questions and then read the alternatives out loud, and noted the score of each answer given by the participant. The interview lasted around 20 minutes. The date for the oral examination was agreed by the examiner and participant after the conclusion of the interview.

The following sociodemographic variables were analyzed: gender, age (complete years), monthly household income (categorized based on the monthly minimum wage in Brazil, which was equal to US\$243.96), and educational status.

For evaluating the impact of oral health on quality of life, the Oral Health Impact Profile (OHIP-14) [28] was used: the Brazilian version in Portuguese [29]. The OHIP-14 contained 14 items in seven dimensions, covering the following: functional limitation, physical pain, psychological discomfort, physical inability, psychological inability, social inability, and incapacity. A scale of one to five points is used for each of the questions (never; almost never; occasionally; almost always; always). The greater the score, the greater the impact on the individual's quality of life [30,31].

\section{Clinical Data Collection}

The clinical examinations of the individuals were performed in the dental offices. A single examiner examined the use of dental prostheses and the extent to which they complied with their functional and aesthetic criteria, using natural light and gauze, with the help of clinical equipment sets containing instruments standardized by the WHO - sterilized mouth mirror and WHO probe (Golgran Ind. e Com. Ltda., São Paulo, SP, Brazil), conducted in accordance with biosafety rules. The presence, type and criteria for conditions of use of dental prostheses were recorded for each jaw.

The aim of the clinical examination was to record whether dental prostheses were present for both upper and lower jaws (complete dentures, removable or fixed partial, single crowns or tooth bridges, or more than one fixed) [26,27]. For those subjects using prostheses, the criteria for functional and aesthetic adequacy of the prostheses were subsequently evaluated [27].

The following points were taken into consideration: whether the prostheses were stable during movements of protrusion, retrusion and laterality; whether there was a movement or rolling when they were gently pressured in the pre-molar region of one side of the dental arch; whether they had retention, whether 
they were tight or loose in relation to the alveolar ridge; whether they re-established the vertical dimension of occlusion obeying the free functional space and re-establishing appropriate visual quality of the patient's facial profile; whether they caused trauma to the patient in any region due to bad fitting or setting; and whether they fractured or stained in any part [27]. Prostheses that showed at least one of these requirements were considered inadequate for use.

\section{Statistical Analysis}

The OHIP-14 dependent variable was dichotomized for statistical analysis, in which zero values were recorded as the absence of impact, and non-zero values as the presence of some impact. The software used for the statistical analysis of the data obtained was the Statistical Package for Social Science (SPSS), v. 21.0 for Windows (SPSS, Inc., Chicago, IL, USA). The Chi-squared $\left(\chi^{2}\right)$ and Fisher's exact tests were used to evaluate the association between the dimensions that comprised the dependent variable (OHIP-14) and the independent variable named 'use of dental prostheses which are not in adequate condition" with a significance level of $5 \%$ and power of 0.80. Prevalence rate ratios (PRR) and a corresponding confidence interval of 95\% (CI 95\%) were calculated.

Ethical Considerations

This study was approved by the Committee on Ethics of Research on Human Beings, obeying Resolution 466/2012, and the Helsinki Principles (CAAE: 42617515.5.0000.5188). All the volunteers signed the free and informed consent form prior to their participation in the study.

\section{Results}

The response rate at the end of the study was $100 \%$. The subjects selected in the sample were aged 60 to 90 , with an average age of $69.86( \pm 6.60)$ years. The majority of the sample was female $(90.5 \%)$, with a predominance of minimum family income of one times the minimum wage (79.6\%), and an education level of up to eight years $(70.1 \%)$. A total of $71.4 \%$ of all subjects used maxillary complete dentures, and $32.7 \%$ used mandibular complete dentures. Moreover, 24.5\% used mandibular partial removable dentures, and $24.5 \%$ maxillary complete dentures. Combinations of maxillary prostheses were used by $2.1 \%$, and mandibular prostheses by $0.7 \%$. A total of $70.3 \%$ of the older adults $(n=102)$ used inadequate prostheses. Of these, $52.8 \%$ used maxillary prostheses and $47.2 \%$ used mandibular prostheses.

Table 1 shows that the users of prostheses with inappropriate conditions of use experienced a higher impact on the quality of life than the users of prostheses that were in good condition. The dimensions of the OHIP-14 associated with the use of unsatisfactory prostheses were: physical pain (PRR $=3.52$; CI $=4.69-2.65$; $\mathrm{p}<0.001)$, psychological discomfort $(\mathrm{PRR}=5.0 ; \mathrm{CI}=5.85-4.26 ; \mathrm{p}<0.001)$, psychological disability $(\mathrm{PRR}=$ $1.71 ; \mathrm{CI}=2.56-1.14 ; \mathrm{p}<0.001)$ and physical disability $(\mathrm{PRR}=1.68 ; \mathrm{CI}=2.37-1.19 ; \mathrm{p}=0.003)$.

Table 1. Impact on the quality of life in elderly individuals that use inadequate prostheses.

\begin{tabular}{|c|c|c|c|c|c|c|c|c|c|}
\hline \multirow{3}{*}{ Dimensions OHIP-14 } & \multicolumn{4}{|c|}{ Dental Prosthesis' Condition } & \multirow{3}{*}{ PRR } & \multirow{3}{*}{ CI } & \multirow{3}{*}{ p-value } & \multirow{3}{*}{ Power\% } & \multirow{3}{*}{ Cohen's h } \\
\hline & \multicolumn{2}{|c|}{ Adequate } & \multicolumn{2}{|c|}{ Inadequate } & & & & & \\
\hline & + & - & + & - & & & & & \\
\hline Functional Limitation & 16 & 29 & 60 & 42 & 1.65 & $1.20-2.2$ & $<0.001$ & 74.8 & 0.47 \\
\hline Physical Pain & 08 & 37 & 64 & 38 & 3.52 & $2.65-4.69$ & $<0.001$ & 99.9 & 0.95 \\
\hline Psychological Discomfort & 03 & 42 & 34 & 68 & 5.00 & $4.26-5.85$ & $<0.001$ & 97.7 & 0.70 \\
\hline
\end{tabular}




\begin{tabular}{lcccccccccc} 
Physical Disability & 17 & 28 & 65 & 37 & 1.68 & $1.19-2.37$ & 0.003 & 83.4 & 0.52 \\
Psychological Disability & 19 & 26 & 74 & 28 & 1.71 & $1.14-2.56$ & $<0.001$ & 93.6 & 0.62 \\
Social Disability & 12 & 33 & 50 & 52 & 1.83 & $1.41-2.38$ & 0.009 & 74.0 & 0.46 & \\
Handicap & 34 & 11 & 96 & 06 & 1.24 & $0.49-1.15$ & 0.002 & 86.0 & 0.54 \\
\hline
\end{tabular}

+: Positive response number in relation to OHIP (feel); -: Negative response number in relation to OHIP (don't feel); PRR: Prevalence Rate Ratios; CI: Confidence Interval.

\section{Discussion}

The results of this study suggest an association between users of inadequate prostheses and impact on quality of life regarding older adult's oral health.

Most of the sample consisted of women. This can be explained by their greater longevity, greater demand for health services and less exposure to risk factors for diseases, as well as greater participation in group activities [32-34]. In relation to the prostheses quality, the inadequate ones may cause an abnormality of oral mucosae such as traumatic ulcers, chronic and inflammatory lesions, and fibrous tissue growth, conditions which may cause physical pain in the mouth or discomfort during chewing and speaking [9]. Some studies have reported the association between inadequate dental prostheses and the presence of lesions in the oral mucosa, such as fibrous hyperplasia and angular cheilitis [35].

Studies revealed that lack of retention and pain in the buccal surfaces of the maxillary tuberosities, buccal and lingual surfaces of mandibular crest are the main cause of complaints by denture wearers [36]. In addition, other authors have revealed that denture wearers with increased occlusal vertical dimension (OVD) generally complain of uncertain pain involving both maxilla and mandible, and a feeling of tiredness in their jaws [37].

Another problem found in the OHIP-14 is the impact on the functional dimension. Users of inadequate prostheses have more difficulty in pronouncing words. A lack of an adequate freeway space is a frequent error in the construction of prostheses, which may cause contact difficulties between the teeth, between teeth and lips, and between teeth and tongue during speech, and thereby prevent sounds being spoken correctly, resulting in pronunciation problems [38]. As a result, users of these prostheses also experience complications of a psychological nature, such as social embarrassment and reduced self-esteem.

When the psychological discomfort and psychological disability dimensions of the OHIP-14 scores were evaluated, those with inadequate prostheses reported a greater sensation of embarrassment during social relationships as a result of the absence of retention and stability in their prostheses. Properly constructed prostheses contribute to enhanced self-esteem, a sense of confidence, and psychological well-being, thus improving social relationships [39]. However, when they are unsatisfactory, they may cause adverse consequences to social life because they make the individual embarrassed, reclusive, and may contribute to depression [40].

Regarding eating difficulties, users of poorly adapted prostheses reported having to interrupt meals in situations that can be related to discomfort resulting from prostheses that are unstable during chewing. Users of old and inadequate prostheses suffer since they need to change their food to more creamy/soft ingredients with less nutritional value, since pain and discomfort do not allow consistent chewing of food, therefore directly influencing the quality of life and life expectancy [41].

In this study, it was observed that the majority of all subjects used complete maxillary and partial dentures, and $58.2 \%$ of these were evaluated as inadequate prostheses in female patients. From this, it is suggested that they were mainly constructed for their aesthetic aspect in order to reestablish their smile and social relationship but in detriment to functional aspects, and this appears to relate to the concept of women 
being more concerned with their appearance than men. This situation demonstrates the importance given to aesthetic standards to satisfy psychological mechanisms, which increase an individual's self-esteem [42]. A lack of teeth makes women sad and embarrassed, and therefore they use inadequate dentures to soften their shame and raise their self-esteem for coexistence in society [43].

The majority of older adults in the study had low levels of income and education. It is believed that the need for information and the inequity in access to dental rehabilitation treatments may be factors, which contribute to the high number of older adults using inadequate prostheses. Brazil still needs to consolidate its oral healthcare network, giving priority to universal access to the services in the three levels of healthcare, especially for those of the dental specializations in order to be able to provide satisfactory oral rehabilitation services to those that need them [18]. Disabilities are also critical because older adults declared to have a less satisfactory life due to tooth loss. This data demonstrates that prosthesis users noticed their lack of aesthetic and functional requirements [44].

The ridge anatomy may influence the prosthesis stability, when it severely resorbs the mandibular bone, or when it interferes with muscular insertions, which hinders the prosthesis stability during its function [45]. Patients who discontinue dental prostheses use, especially mandibular dentures, often suffer from lack of retention and stability and from these incapacities to adapt to the partial and total prosthesis in these cases $[46,47]$.

Studies carried out in Brazil have shown an increase in the supply of LRPD, being unequal among macroregions, as well as their productions seem discrepant, given the epidemiological profile of the population [48]. The use of dental services is not only dependent of their supply or the patient's need, but above all on self-perception in oral health that influences the subject to seek oral health services [20]. Thus, there is a need to organize the Oral Health network, with increased supply and installed capacity, training of professionals, improvement of the Reference System, from basic care to the supply of dental prostheses, aiming at the integrality of health care and increase in the system resolution capacity. This study has some limitations, which are inherent in its design, since it is a transversal sample performed in a single metropolitan city, and the interview responses could have been subject to information bias. Also, confounding variables such as mucosal lesions and poor oral hygiene associated with the use of prostheses could influence the results.

Risk of bias may influence the results of this type of study since poor quality of life can lead to negligence of the dental prosthesis or inadequate dental prostheses can influence the quality of life of older adults. Therefore, longitudinal studies, which add other variables and involve more heterogeneous samples, are essential for clarifying the causal relationship and edentulism impact on the oral health of older subjects.

This study provides important information on the oral health needs of an older adult population, with a view to better organize the services which provide dental care to this portion of the population to enable these services to supply care that is specialized, universal and effective, having a positive effect on the quality of life of those who are edentulous and currently suffer from a lack of properly accurate oral rehabilitation.

\section{Conclusion}

The use of inadequate prostheses had an effect on the quality of life of analyzed older adult population. The most affected OHIP-14 dimensions were: physical pain in the oral region, psychological discomfort, psychological disability, and physical disability. Therefore, services, which provide health care for older adults, should overcome this reality by providing broad access to oral rehabilitation that is appropriate to the needs of each individual. 


\section{Authors' Contributions}

\begin{tabular}{|c|c|c|}
\hline MAS & (iD) $0000-0002-8837-6699$ & $\begin{array}{l}\text { Conceptualization, Methodology, Investigation, Formal Analysis and Writing - } \\
\text { Original Draft Preparation. }\end{array}$ \\
\hline AUDB & (iD) $0000-0003-1593-0174$ & Conceptualization, Formal Analysis and Writing - Review and Editing. \\
\hline MHGA & (iD) $0000-0001-8794-5725$ & Formal Analysis and Writing - Review and Editing. \\
\hline FDSF & (iD) 0000-0003-4237-0184 & Conceptualization, Formal Analysis and Writing - Review and Editing. \\
\hline
\end{tabular}

\section{Financial Support}

None.

\section{Conflict of Interest}

The authors declare no conflicts of interest.

\section{References}

[1] Sheiham A. Oral health, general health and quality of life. Bull World Health Organ 2005; 83(9):644. https://doi.org//So042-96862005000900004

[2] Niesten D, van Mourik K, van der Sanden W. The impact of having natural teeth on the QoL of frail dentulous older people. A qualitative study. BMC Public Health 2012; 12:839. https://doi.org/10.1186/1471-2458-12-839

[3] Bulgareli JV, Faria ET, Cortellazzi KL, Guerra LM, Meneghim MC, Ambrosano GMB, et al. Factors influencing the impact of oral health on the daily activities of adolescents, adults and older adults. Rev Saúde Pública 2018; 52:44. https://doi.org/10.11606/s1518-8787.2018052000042

[4] Skaar DD, O’ Connor H. Dental service trends for older US adults, 1998-2006. Spec Care Dentist 2012; 32(2):42-8. https://doi.org/10.1111/j.1754-4505.2012.00239.x

[5] Guerra MJC, Greco RM, Leite ICG, Ferreira e Ferreira E, de Paula MV. Impact of oral health conditions on the quality of life of workers. Ciênc Saúde Coletiva 2014; 19(12):4777-86.

https://doi.org/10.1590/1413-812320141912.21352013

[6] Jenei A, Sándor J, Hegedus C, Bágyi K, Nagy L, Kiss C, et al. Oral health-related quality of life after prosthetic rehabilitation: a longitudinal study with the OHIP questionnaire. Health Qual Life Outcomes 2015; 13:99. https://doi.org/10.1186/s 12955-015-0289-2

[7] Polzer I, Schawahn C, Volzke H, Mundt T, Biffar R. The association of tooth loss with all-cause and circulatory mortality. Is there a benefit of replaced teeth? A systematic review and meta-analysis. Clin Oral Investig 2012; 16(2):333-51. https://doi.org/10.1007/s00784-01 1-0625-9

[8] Silva DD, Held RB, Torres SVS, Sousa MLR, Neri AL, Antunes JLF. Autopercepção da saúde bucal em idosos e fatores associados em Campinas, SP, 2008-2009. Rev Saúde Pública 2011; 45(6):1145-53. https://doi.org/10.1590/So034-89102011005000068

[9] Carvalho MV, Iglesias DP, do Nascimento GJ, Sobral AP. Epidemiological study of 534 biopsies of oral mucosal lesions in elderly Brazilian patients. Gerodontology 2011;28(2):111-5.

https://doi.org/10.1111/j.1741-2358.2010.00370.x

[10] Martins AMEBL, Barreto SM, Silveira MF, Santa-Rosa TTA, Pereira RD. Self-perceived oral health among Brazilian elderly individuals. Rev Saúde Pública 2010; 44(5):912-22. https://doi.org/10.1590/So034-89102010005000028

[11] Nunes CL, Abegg C. Factors associated with oral health perception in older Brazilians. Gerodontology 2008; 25(1):42-8. https://doi.org/10.1111/j.1741-2358.2007.00163.x

[12] Machado FCA, Costa APS, Pontes ALB, Lima KC, Ferreira MAF. Daily difficulties associated with full conventional dentures. Ciênc Saúde Coletiva 2013; 18(10):3091-100. https://doi.org/10.1590/S1413-81232013001000034

[13] Critchlow SB, Ellis JS. Progostic indicators for conventional complete denture therapy: a review of literature. J Dent 2010; 38(1):2-9. https://doi.org/10.1016/j.jdent.2009.08.004

[14] Bagewitz IC, Soderfeldt B, Palmqvist S, Nilner K. Oral prostheses and oral health- related quality of life: a survey study of an adult Swedish population. Int J Prosthodont 2007; 20(2):132-42.

[15] Shigli K, Hebbal M. Assessment of changes in oral health related quality of life among patients with complete denture before and 1-month post-insertion using Geriatric Oral Health Assessment Index. Gerodontology 2010; 27(3):16773. https://doi.org/10.1111/j.1741-2358.2009.00323.x

[16] Komagamine Y, Kanazawa M, Kaiba Y, Sato Y, Minakuchi S, Sasaki Y. Association between self-assessment of complete dentures and oral health-related quality of life. J Oral Rehabil 2012; 39(11):847-57. https://doi.org/10.1111/joor.12004 
[17] Kotciuk L, Godlewskie T. Oral health-related quality of life of patients using removable dentures - review of literature. Dent Med Probl 2015; 52(2):222-6.

[18] Pucca GA Jr, Gabriel M, de Araújo ME, de Almeida FC. Ten years of national oral health policy in Brazil: innovation, boldness, and numerous challenges. J Dent Res 2015; 94(10):1333-7. https://doi.org/10.1 177/0022034515599979

[19] Brasil. Ministério da Saúde. Portaria no. 599, de 24 de março de 2006. Define a implantação de Especialidades Odontológicas (CEO) e de Laboratórios Regionais de Próteses Dentárias (LRPDs) e estabelecer critérios, normas e requisitos para seu credenciamento. Diário Oficial da União 24 mar. 2006. [In Portuguese]

[20] Rebelo MAB, Emmi DT, Herkrath FJ, Meira GF, Goes PSA, Vettore MV. Need of dental prosthesis in older people and the offer of specialized care in the Unified Health System, Brazil. Pesqui Bras Odontopediatria Clín Integr 2018; 18(1):e3201. https://doi.org/10.4034/PBOCI.2018.181.38

[21] Chaves SCL, Almeida AMFL, Rossi TRA, Santana SF, Barros SG, Santos CML. Oral health policy in Brazil between 2003 and 2014: scenarios, proposals, actions, and outcomes. Ciênc Saúde Coletiva 2017; 22(6):1791-803 https://doi.org/10.1590/1413-81232017226.18782015

[22] Soares FF, Chaves SCL, Cangussu MCT. Local government and public dental health services: an analysis of inequality in use. Cad Saúde Pública 2015; 31 (3):586-96. https://doi.org/10.1590/0102-311 x00077214

[23] Scott BJ, Hunter RV. Creating complete dentures that are stable in function. Dent Update 2008; 35(4):259-62, 265-7. https://doi.org/10.12968/denu.2008.35.4.259

[24] Vandenbroucke JP, von Elm E, Altman DG, Gøtzsche PC, Mulrow CD, Pocock SJ, et al. Strengthening the Reporting of Observational Studies in Epidemiology (STROBE): explanation and elaboration. Int J Surg 2014; 12(12):1500-24. https://doi.org/10.1016/j.ijsu.2014.07.014

[25] Brasil. Ministério da Saúde. Secretaria de Atenção à Saúde. Departamento de Atenção Básica. Coordenação de Saúde Bucal. Projeto SB Brasil 2010. Resultados Principais. Brasília: MS; 2010. [In Portuguese]

[26] World Health Organization. Oral Health Surveys: Basic Methods. 4th ed. Geneva: WHO; 1997.

[27] Slade GD, Spencer AJ. Development and evaluation of oral health impact profile. Community Dent Health 1994; 11(1):3-11.

[28] Oliveira BH, Nadanovsky P. Psychometric properties of the Brazilian version of the Oral Health Impact Profile- short form. Community Dent Oral Epidemiol 2005; 33 (4):307-14. https://doi.org/10.1111/j.1600-0528.2005.00225.x

[29] Slade GD. Derivation and validation of a short-form Oral Health Impact Profile. Community Dent Oral Epidemiol 1997; 25(4):284-90. https://doi.org/10.1111/j.1600-0528.1997.tbo0941.x

[30] Locker D. Measuring oral health: a conceptual framework. Community Dent Health 1988; 5 (1):3-18.

[31] Brasil. Ministério da Saúde (MS). Secretaria de Políticas de Saúde. Departamento de Atenção Básica. Coordenação Nacional de Saúde Bucal. Projeto SB Brasil 2010: Pesquisa Nacional de Saúde Bucal: Manual da Equipe de Campo. Brasília: MS; 2009. [In Portuguese]

[32] Baldani MH, Brito WH, Lawder JAC, Mendes YBE, Silva FFM, Antunes JLF. Individual determinants of dental care utilization among low-income adult and elderly individuals. Rev Bras Epidemiol 2010; 13(1):150-62. https://doi.org/10.1590/S1415-790X2010000100014

[33] Silva MES, Villaça EL, Magalhães CS, Ferreira EF. Impact of tooth loss in quality of life. Ciênc Saúde Coletiva 2010; 15(3):841-50 https://doi.org/10.1590/S1413-81232010000300027

[34] Valim-Rogatto PC, Rogatto GP, Candolo C, Machado AA, Brêtas ACP. Participação de idosos em atividades físicas, sociais, educacionais e em serviços de saúde de centro de convivência: diferença entre sexos. Coleção Pesqui Educ Fís 2010; 9(3):169-76. [In Portuguese]

[35] Freitas JB, Gomez RS, de Abreu MH, Ferreira e Ferreira E. Relationship between the use of full dentures and mucosal alterations among elderly Brazilians. J Oral Rehabil 2008; 35(5):370-4. https://doi.org/10.1111/j.1365-2842.2007.01782.x

[36] Sheppard IM, Schwartz LR, Sheppard SM. Oral status of edentulous and complete denture-wearing patients. J Am Dent Assoc 1971; 83(3):614-20. https://doi.org/10.14219/jada.archive.1971.0376

[37] Bilhan H, Erdogan O, Ergin S, Celik M, Ates G, Geckili O. Complication rates and patient satisfaction with removable dentures. J Adv Prosthodont 2012; 4(2):109-15. https://doi.org/10.4047/jap.2012.4.2.109

[38] Fouda SM, Al-Attar MS, Virtanen JI, Raustia A. Effect of patient's personality on satisfaction with their present complete denture and after increasing the occlusal vertical dimension: a study of edentulous Egyptian patients. Int $\mathrm{J}$ Dent 2014; 2014:1-7. https://doi.org/10.1155/2014/635943

[39] Orestes-Cardoso S, Passos KKM, Nascimento SLC, Melo MVS, Trindade MO. Ideational representations of edentulism and prosthetic rehabilitation from the point of view of the elderly. Rev Bras Prom Saúde 2015; 28(3):394401 .

[40] Medeiros SL, Ponte MPB, Júnior-Magalhães HV. Self-perception of chewing ability in elderly. Rev Bras Geriatr Gerontol 2014; 17(4):807-17. https://doi.org/10.1590/1809-9823.2014.13150

[41] Bortoli FR, Moreira MA, Moretti-Pires RO, Botazzo C, Kovaleski DF. Perception of oral health in women with extensive dental losses. Saúde Soc 2017; 26 (2):533-44. https://doi.org/10.1590/s0104-12902017162160

[42] Arizola HGA, Brescovici SM, Delgado SE, Ruschle CK. Face changes on patients after aesthetic speech therapy treatment in school-practice of speech therapy. Rev CEFAC 2012; 14(6):1167-82. 
https://doi.org/10.1590/S1516-18462012005000041

[43] Friedman N, Landesman HM, Wexler M. The influences of fear, anxiety, and depression on the patient's adaptive responses to complete dentures. Part I. J Prosthet Dent 1987; 58(6):687-9.

https://doi.org/10.1016/0022-3913(87)90419-7

[44] Zhang Q, Witter DJ, Gerritsen AE, Bronkhorst EM, Creugers NH. Functional dental status and oral health-related quality of life in an over 40 years old Chinese population. Clin Oral Invest 2013; 17(6):1471-80. https://doi.org/10.1007/s00784-012-0834-x

[45] Ribeiro JAM, Resende CMBM, Lopes ALC, Farias-Neto A, Carreiro AFP. The influence of mandibular ridge anatomy on treatment outcome with conventional complete dentures. Acta Odontol Latinoam 2014; 27(2):53-7.

[46] Costa AP, Machado FC, Pereira AL, Carreiro AFP, Ferreira MA. Technical quality and satisfaction related to full conventional dentures. Ciênc Saúde Colet 2013; 18(2):453-60. https://doi.org/10.1590/s 1413-81232013000200016

[47] Carlsson GE, Omar R. The future of complete dentures in oral rehabilitation. A critical review. J Oral Rehabil 2010; 37(2):143-56. https://doi.org/10.1111/j.1365-2842.2009.02039.x

[48] Aguiar VR, Celeste RK. The need for, and allocation of, regional prosthodontics laboratories in Brazil: an exploratory study. Ciênc Saúde Coletiva 2015; 20(10):3121-8. https://doi.org/10.1590/1413-812320152010.18212014 